\section{Connecting the dots in translational research}

\author{
Jonathan D. Kahn
}

Translational research is currently one of the top priorities for the US National Institutes of Health (NIH), as recently highlighted by its Director, Francis Collins (An audience with... Francis Collins. Nature Rev. Drug Discov. 10, $14(2011))^{1}$. The rise of this concept has been fuelled by the widely held belief that major investments in basic biomedical research will not bear fruit in terms of new medicines without new initiatives or approaches to bridge the 'valley of death' that is considered to be a key cause for the stalling of industry pipelines. Indeed, such is the power of this concept that it has recently led to structural reconfiguration of the NIH to create the National Center for Advancing Translational Sciences (NCATS), which was formally authorized by the US Congress in December 2011. The fiscal year 2012 budget for the NCATS was $\sim$ US\$574 million and it is requesting $\sim \$ 639$ million for 2013 (REF. 2).

Collins and Thomas Insel, the Acting Director of the NCATS, have emphasized that the NCATS is not a governmentsponsored drug company and that its activities will complement, not compete with, other drug development efforts, acting in a "precompetitive space" where it can "de-risk" certain avenues of research (see the NCATS website). The idea is that more directed, federally supported efforts, for example, to rescue and repurpose existing drugs, to predict toxicity or to identify and validate drug targets, will reinvigorate the flow of new medicines (see the NCATS website).

In principle, although government support of efforts in these areas could have substantial value, this reorientation of bureaucracy and commitment of resources may be based on some flawed or, at the least, incomplete assumptions about the reasons why the pipeline of new medicines has not met expectations. Two recent studies, one concerning the productivity crisis in pharmaceutical research and development (R\&D), the other examining preclinical cancer research, when viewed in relation to each other, raise some troubling questions about the logic underlying the NCATS.

The first article, by Pammolli and colleagues $^{3}$, argues that the decline in the productivity of pharmaceutical R\&D may be explained, in part, by an increasing focus on developing drugs in therapeutic areas that are characterized by a low probability of success (POS). Foremost among these is oncology, which they rank first both as an area of research and of low POS.

The second article, by Begley and Ellis ${ }^{4}$, was animated by a concern over the failure to translate basic cancer research into new therapies, noting that "clinical trials in oncology have the highest failure rate compared with other therapeutic areas". Discussing potential reasons for this high failure rate, they highlight a study conducted by Amgen (in which Begley participated) that tried to confirm published findings in 53 'landmark' studies in oncology (papers in top journals, from reputable laboratories). Of the 53 papers, the Amgen study found that only $6(11 \%)$ could be replicated by company scientists. "It was shocking," Begley told Reuters ${ }^{5}$. "These are the studies the pharmaceutical industry relies on to identify new targets for drug development. But if you're going to place a $\$ 1$ million or $\$ 2$ million or $\$ 5$ million bet on an observation, you need to be sure it's true. As we tried to reproduce these papers we became convinced you can't take anything at face value." Moreover, the findings discussed in the article are consistent with those of a separate analysis - conducted by Bayer HealthCare in Germany - of the reproducibility of published data associated with 67 in-house projects, which found that only about $25 \%$ of published preclinical studies could be validated to the point at which projects could continue 6 . Importantly, 70\% of these studies were also in the area of oncology.

Connecting these studies to the article by Pammolli and colleagues provides some worrying alternative reasons to the commonly held views as to why the drug pipeline may be stalled. If, as Pammolli et al. indicate, pharmaceutical R\&D is increasingly focused on developing cancer drugs and if, as the Amgen and Bayer studies indicate, the majority of studies driving the clinical trials underlying the development of new cancer drugs could be flawed, then perhaps the 'valley of death' the NCATS is seeking to bridge has not been primarily caused by a lack of translational research but by fundamental problems in the way basic research is being conducted.

Perhaps as significant as the findings of the Amgen study are what Begley and Ellis identify as possible causes of the problem with preclinical research, as highlighted in the Amgen study. They note that the investigators studied "were all competent, well-meaning scientists who truly wanted to make advances in cancer research". The problems, they hypothesize, were more structural and individual. They note that ${ }^{4}$ : "To obtain funding, a job, promotion or tenure, researchers need a strong publication record, often including a firstauthored high-impact publication. Journal editors, reviewers and grant-review committees often look for a scientific finding that is simple, clear and complete - a 'perfect' story. It is therefore tempting for investigators to submit selected data sets for publication, or even to massage data to fit the underlying hypothesis."

In recent years, as biomedicine appears to be increasingly viewed as a golden goose for major research universities, additional incentives might be driving the premature publication of results that enhance both academic standing and opportunities for commercialization of the research. Most obvious in this regard has been the rise in patent applications originating from research universities and the concomitant rise of industry-academia collaboration ${ }^{7}$. Indeed, the NCATS is among a wave of initiatives that have embraced the idea of industryacademia collaborations in translational research.

However, given the findings of the Amgen study, the NCATS might not actually be targeting a key problem underlying the 'valley of death' - the lack of robustness in preclinical research. Indeed, if Begley and Ellis are correct, then uncritically viewing translational research as a panacea, and directing federal funding accordingly, may be feeding into the unhealthy dynamic that incentivized the production of insufficiently robust research in the first place, potentially exacerbating the problem it hopes to address.

This is not to say that translational research should not be pursued in academia, nor that industry-academia collaboration should be avoided. It is, rather, a call for a more complete examination of the assumptions underlying the creation of the NCATS and a consideration of whether its framing 
of the problems of drug development, and hence its resulting structure and incentive system, needs to be rethought in light of the issues discussed above.

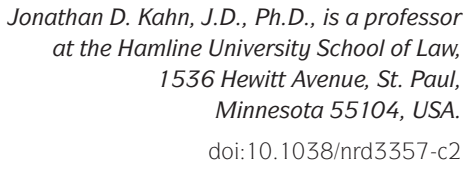

Jonathan D. Kahn, J.D., Ph.D., is a professor at the Hamline University School of Law, 1536 Hewitt Avenue, St. Paul, Minnesota 55104, USA. doi:10.1038/nrd3357-c2

1. Mullard, A An audience with Francis Collins. Nature Rev. Drug Discov. 10, 14 (2011).

2. Insel, T. Fiscal Year 2013 Budget Request. US National Institutes of Health (NIH) [online], www.nih.gov/about/

director/budgetrequest/fy2013_insel_house.pdf (2012).

3. Pammolli, F., Magazzini, L. \& Riccaboni, M. The productivity crisis in pharmaceutical R\&D. Nature Rev Drug Discov. 10, 428-438 (2011).

4. Begley, C. G. \& Ellis, L. M. Drug development: raise standards for preclinical cancer research. Nature 483, 531-533 (2012).

5. Reuters. Many cancer studies produce unreliable results: study. CNBC news [online],
http://www.cnbc.com/id/46882434/Many_Cancer Studies_Produce_Unreliable_Results_Study (28 Mar 2012)

6. Prinz, F., Schlange, T. \& Asadullah, K. Believe it or not: how much can we rely on published data on potential drug targets? Nature Rev. Drug Discov. 10, 712 (2011).

7. Boccanfuso, A. M. Why university-industry partnerships matter. Sci. Transl. Med. 2, $51 \mathrm{~cm} 25$ (2010).

Competing interests statement

The author declares no competing financial interests 